Research Article

\title{
Cytogenetical studies in five Atlantic Anguilliformes fishes
}

\author{
Antonio Jales Moraes Vasconcelos and Wagner Franco Molina \\ Departamento de Biologia Celular e Genética, Centro de Biociências, \\ Universidade Federal do Rio Grande do Norte, Natal, RN, Brazil.
}

\begin{abstract}
The order Anguilliformes comprises 15 families, 141 genera and 791 fish species. Eight families had at least one karyotyped species, with a prevalence of $2 n=38$ chromosomes and high fundamental numbers (FN). The only exception to this pattern is the family Muraenidae, in which the eight species analyzed presented $2 \mathrm{n}=42 \mathrm{chromo}-$ somes. Despite of the large number of Anguilliformes species, karyotypic reports are available for only a few representatives. In the present work, a species of Ophichthidae, Myrichthys ocellatus $(2 \mathrm{n}=38 ; 8 \mathrm{~m}+14 \mathrm{sm}+10 \mathrm{st}+6 \mathrm{a}$; $\mathrm{FN}=70)$ and four species of Muraenidae, Enchelycore nigricans $(2 \mathrm{n}=42 ; 6 \mathrm{~m}+8 \mathrm{sm}+12 \mathrm{st}+16 \mathrm{a} ; \mathrm{FN}=68)$, Gymnothorax miliaris $(2 \mathrm{n}=42 ; 14 \mathrm{~m}+18 \mathrm{sm}+10 \mathrm{st} ; \mathrm{FN}=84)$, G. vicinus $(2 \mathrm{n}=42 ; 8 \mathrm{~m}+6 \mathrm{sm}+28 \mathrm{a} ; \mathrm{FN}=56)$ and Muraena pavonina $(2 n=42 ; 6 m+4 s m+32 a ; F N=52)$, collected along the Northeastern coast of Brazil and around the St Peter and St Paul Archipelago were analyzed. Typical large metacentric chromosomes were observed in all species. Conspicuous polymorphic heterochromatic regions were observed at the centromeres of most chromosomes and at single ribosomal sites. The data obtained for Ophichthidae corroborate the hypothesis of a karyotypic diversification mainly due to pericentric inversions and Robertsonian rearrangements, while the identification of constant chromosome numbers in Muraenidae $(2 n=42)$ suggests a karyotype diversification through pericentric inversions and heterochromatin processes.
\end{abstract}

Key words: Anguilliformes, fish cytogenetics, Muraenidae, Ophichthidae.

Received: March 10, 2008; Accepted: September 5, 2008.

\section{Introduction}

Cytogenetic analyses in fish have allowed to determine sex chromosomes (Moreira-Filho et al., 1993; Devlin and Nagahama, 2002; Molina and Galetti, 2007), the characterization of vertebrate models, like the zebrafish (Sola and Gornung, 2001), the evaluation of genetically modified lineages (Porto-Foresti et al., 2004), and to perform inferences on cytotaxonomic (Bertollo et al., 2000; Bertollo et al., 2004) and evolutionary issues (Demirok and Ünlü, 2001), besides the detection of cryptic species (MoreiraFilho and Bertollo, 1991). Nevertheless, cytogenetic data are still restricted for some fish groups, such as Anguilliformes, which comprises 15 families, 141 genera and 791 species (Nelson, 2006) and are popularly known as eels, congers or morays. Analyses of the $12 \mathrm{~S}$ rRNA sequences support the monophyly of the Anguilliformes, but the phylogenetic relationships within the Order deduced from DNA analysis do not agree with those established through morphological comparisons (Wang et al., 2003).

Previous chromosomal studies in Mediterranean moray species showed that constitutive heterochromatin

Send correspondece to Wagner Franco Molina. Departamento de Biologia Celular e Genética, Centro de Biociências, Universidade Federal do Rio Grande do Norte, Campus Universitário, 59078-970 Natal, RN, Brazil. E-mail: molinawf@yahoo.com.br. was distributed on and around all the centromeres (Deiana et al., 1990). A remarkable heteromorphism was reported between the NOR-bearing homologues in several species (Cau et al., 1988), which in some cases led to the misidentification of this pair as sex chromosomes (Wiberg, 1983).

Although they represent some of the most typical reef fish groups in the Atlantic Ocean, few cytogenetic studies have been carried out in Muraenidae and Ophichthidae. In this work we performed a cytogenetic analysis of Myrichthys ocellatus (Ophichthidae), Enchelycore nigricans, Gymnothorax vicinus, Gymnothorax miliaris and Muraena pavonina (Muraenidae) collected in the Brazilian coast and around Atlantic oceanic islands, using conventional staining, Ag-NOR and C-banding.

\section{Material and Methods}

The goldspotted snake eel Myrichthys ocellatus (12 specimens, undefined sex) and the purplemouth moray Gymnothorax vicinus (8 specimens, undefined sex) were collected along the shore of the state of Rio Grande do Norte (6²'10" S/356'42" W), whereas specimens of golden-tail moray Gymnothorax miliaris (2 females) were collected in the coastline of Salvador $\left(12^{\circ} 58^{\prime} \mathrm{S} / 38^{\circ} 31^{\prime} \mathrm{W}\right)$, state of Bahia, northeastern Brazil. The viper moray Enchelycore nigricans (4 females and 2 males) and the 
white-spotted moray Muraena pavonina (6 females) were collected around the St Peter and St Paul Archipelago $\left(0^{\circ} 55^{\prime} 02^{\prime \prime} \mathrm{N} / 29^{\circ} 20^{\prime} 42^{\prime \prime} \mathrm{W}\right)$.

The individuals were mitotically stimulated for $24 \mathrm{~h}$ by intraperitoneal inoculation of either Munolan ${ }^{\circledR}$ (Allergan Frumtost), an association of fungal and bacterial antigens (Molina, 2002), or yeast suspension (Sacharomyces cerevisae) (Lee and Elder, 1980).

Chromosome preparations were obtained from kidney cells according to Gold et al. (1990). The sex of individuals was determined through macroscopic observation of gonads and histological analyses. The nucleolar organizer regions (NORs) were identified by silver nitrate staining (Howell and Black, 1980) and heterochromatic regions were evidenced after C-banding (Sumner, 1972).

The best metaphases were photographed using a digital system coupled to an Olympus BX42 microscope with $1,000 \mathrm{X}$ magnification. The chromosome pairs were arranged in decreasing size order and classified in relation to the centromere position as metacentric (m), submetacentric (sm), subtelocentric (st) or acrocentric (a) (Levan et al., 1964).

\section{Results}

The Anguilliformes species analyzed presented typical large chromosomes, ranging from 1.2 to $10 \mu \mathrm{m}$, and remarkably asymmetric karyotypes. Sex-related chromosomal heteromorphism was absent in E. nigricans.

Myrichthys ocellatus, the only Ophichthidae analyzed, presented a karyotype with $2 \mathrm{n}=38$ composed of $8 \mathrm{~m}+14 \mathrm{sm}+10 \mathrm{st}+6 \mathrm{a}(\mathrm{FN}=70)$ (Figures 1a, b). A size heteromorphism unrelated to the NORs was sometimes present in the largest chromosome pair of this species (Figure 1a). Remarkable heteromorphisms were also present in the other analyzed species.

Amongst the Muraenidae, Gymnothorax miliaris showed $2 \mathrm{n}=42$ chromosomes, with $14 \mathrm{~m}+18 \mathrm{sm}+10$ st and a high fundamental number $(F N=84)$ (Figures $2 a, b)$. The homologues of pairs 1,8 and 17 often presented significant differences in size (Figure 2a). A diploid number of $2 n=42$ $(\mathrm{FN}=56)$ and a karyotype formula with $8 \mathrm{~m}+6 \mathrm{sm}+28 \mathrm{a}$ were observed in G. vicinus (Figures 3a, b). Some chromosome pairs, such as pairs 1 and 2, showed homologues of different sizes. The karyotype of Enchelycore nigricans was composed of $6 \mathrm{~m}+8 \mathrm{sm}+12 \mathrm{st}+16 \mathrm{a}(\mathrm{FN}=68)($ Figures $4 \mathrm{a}, \mathrm{b})$, while Muraena pavonina, presented a higher number of acrocentric chromosomes and a karyotype formula of $6 \mathrm{~m}+4 \mathrm{sm}+32 \mathrm{a}(\mathrm{FN}=52)($ Figures $5 \mathrm{a}, \mathrm{b})$.

All species presented single Ag-NOR sites, but located at different positions (see boxes in Figures 1 through 5). Ag-NORs were located on the short arms of pair 13 (a) in M. ocellatus; in an interstitial position on the long arms of pair 11 (a) in G. vicinus and on the short arms of the pair $12(\mathrm{sm})$ in G. miliaris. Ribosomal sites were identified on
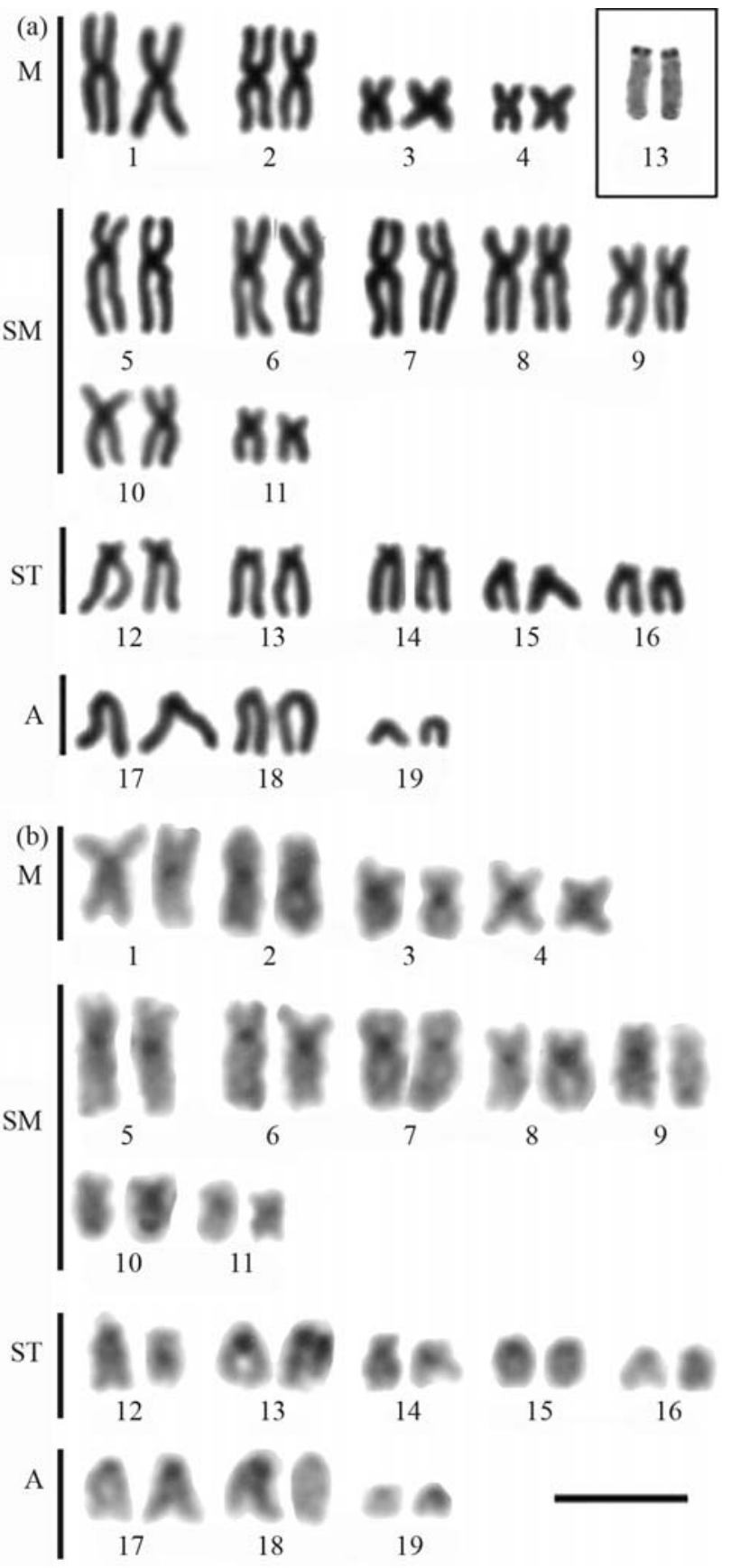

Figure 1 - Karyotype of Myrichthys ocellatus after: (a) Giemsa conventional staining, Inbox, the NOR-bearing pair; (b) C-banding. Bar $=10 \mu \mathrm{m}$.

the short arms of pair 11 (st) in E. nigricans and on the short arms of pair 12 (sm) in M. pavonina.

C-banding revealed heterochromatic regions at the centromeric regions of all chromosomes in all the species (Figures 1 through 5, b). After C-banding, a conspicuous size heteromorphism in the heterochromatin on short arms of pair 8 (Figure 2e) and on pair 12, coinciding with the Ag-NORs, was observed in one female G. miliaris. Telomeric heterochromatic segments were less frequent and 

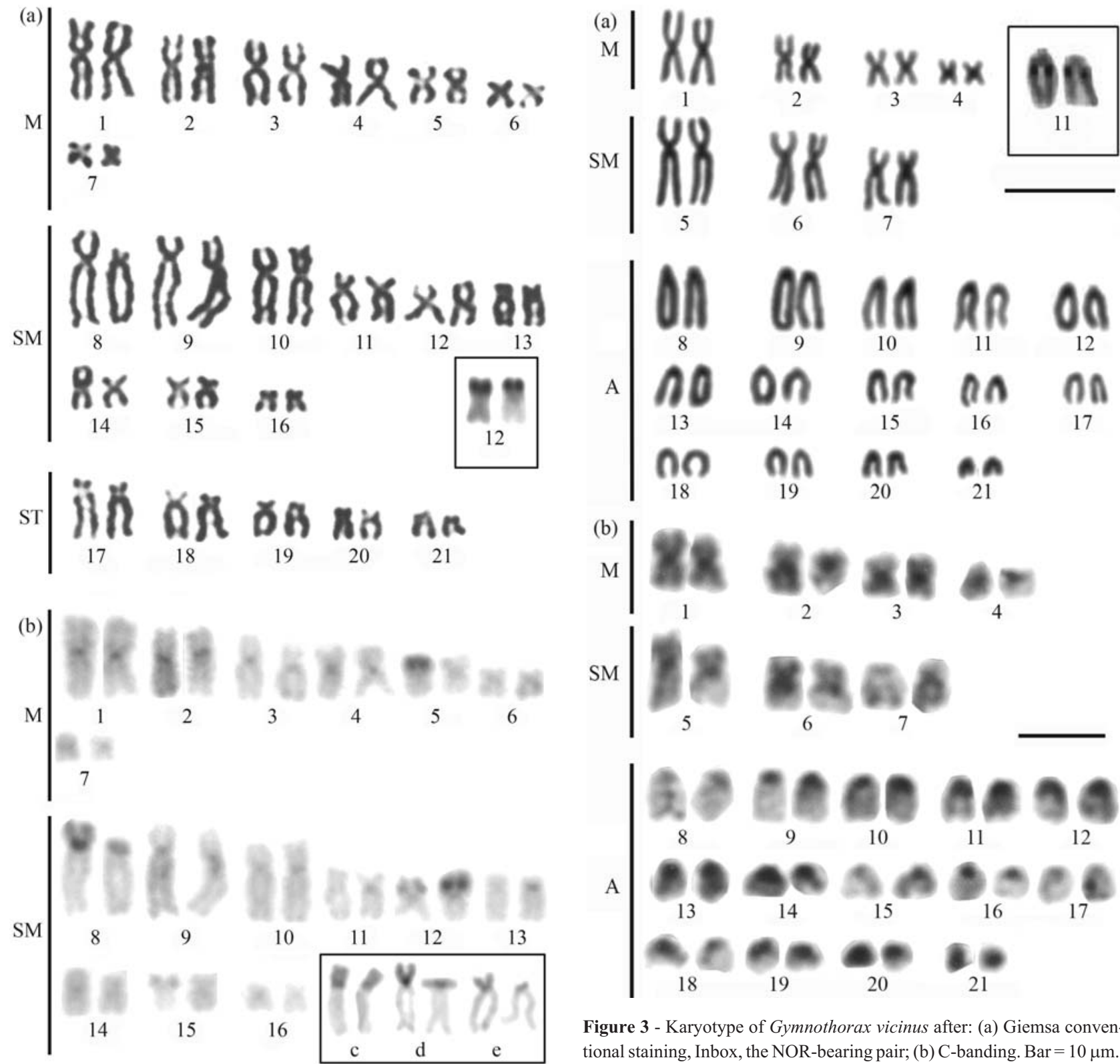

Figure 3 - Karyotype of Gymnothorax vicinus after: (a) Giemsa conventional staining, Inbox, the NOR-bearing pair; (b) C-banding. Bar $=10 \mu \mathrm{m}$.

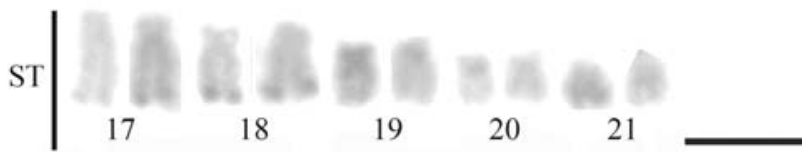

Figure 2 - Karyotype of Gymnothorax miliaris after: (a) Giemsa conventional staining, Inbox, the NOR-bearing pair; (b) C-banding, Non-polymorphic (c-d) and polymorphic (e) heterochromatic regions on the short arms of pair 8 . Bar $=10 \mu \mathrm{m}$.

were evidenced in E. nigricans (pairs 14 and 15) and in $G$. miliaris (pairs 12, 15, 17, 18 and 21) (Figure 2b).

\section{Discussion}

A remarkable level of karyotypic diversification is found within Anguilliformes. The diploid number in this order ranges from $2 \mathrm{n}=26$ to $2 \mathrm{n}=54$ (Klinkhardt et al.,

1995), with variable karyotypic formulae and a high number of biarmed chromosomes.

Low diploid numbers $(2 n=38)$ and a high number of meta-submetacentric chromosomes seem to be the most common condition for Ophichthidae species (Table 1). Species of the families Muraenesocidae, Congridae (Salvadori et al., 1994), Anguillidae (Sola et al., 1980; Sola et al., 1984) and Echelidae (Amores et al., 1995) also share a similar karyotypic pattern. Phylogenetic affinities based on the C- and G-banding patterns have also been proposed for the families Anguillidae and Congridae (Salvadori et al., 1994).

A similar karyotype was also reported in M. ocellatus $(2 \mathrm{n}=38)$ that presented a typical karyotype formula, with mostly biarmed chromosomes $(\mathrm{FN}=70)$. Discordant diploid numbers were identified in Echelus uropterus 
(a)

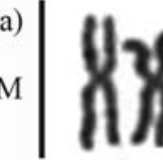

1

$\operatorname{sM} \mid$

ST

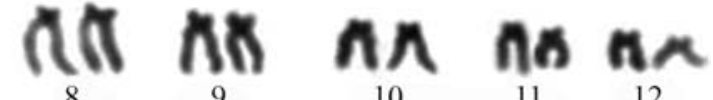

NA

13

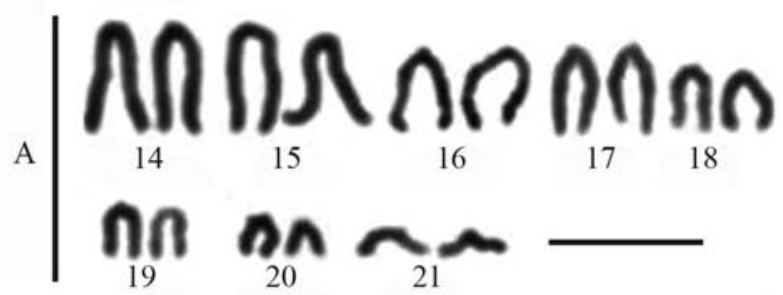

(b)

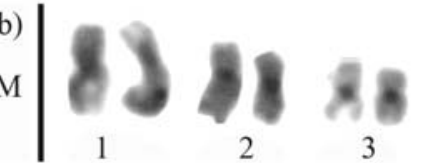

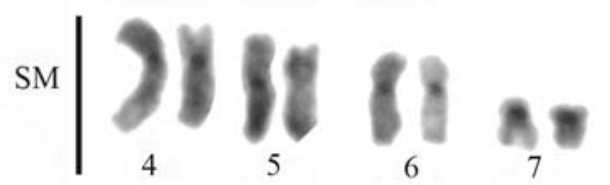

ST $\mid$\begin{tabular}{l|l}
8 \\
8
\end{tabular}
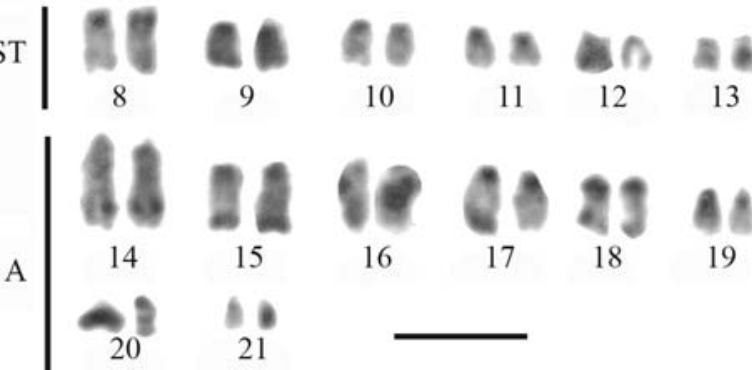

Figure 4 - Karyotype of Enchelycore nigricans after: (a) Giemsa conventional staining, Inbox, the NOR-bearing pair; (b) C-banding. Bar $=10 \mu \mathrm{m}$.

$(2 \mathrm{n}=50)$ (Nogusa, 1960) and Muraenichthys gymnotus $(2 \mathrm{n}=48)$ (Murofushi and Yosida, 1984). The karyotypical diversity reported in the family Ophichthidae has been mainly related to pericentric inversions and Robertsonian rearrangements (Takai and Ojima, 1985). A molecular phylogeny based on $12 \mathrm{~S}$ ribosomal RNA sequences indicated Ophichthidae to be more derived than Muraenidae (Wang et al., 2003).

Amongst Muraenidae, which comprises nearly 200 species, the available cytogenetic data suggest a basal dip-
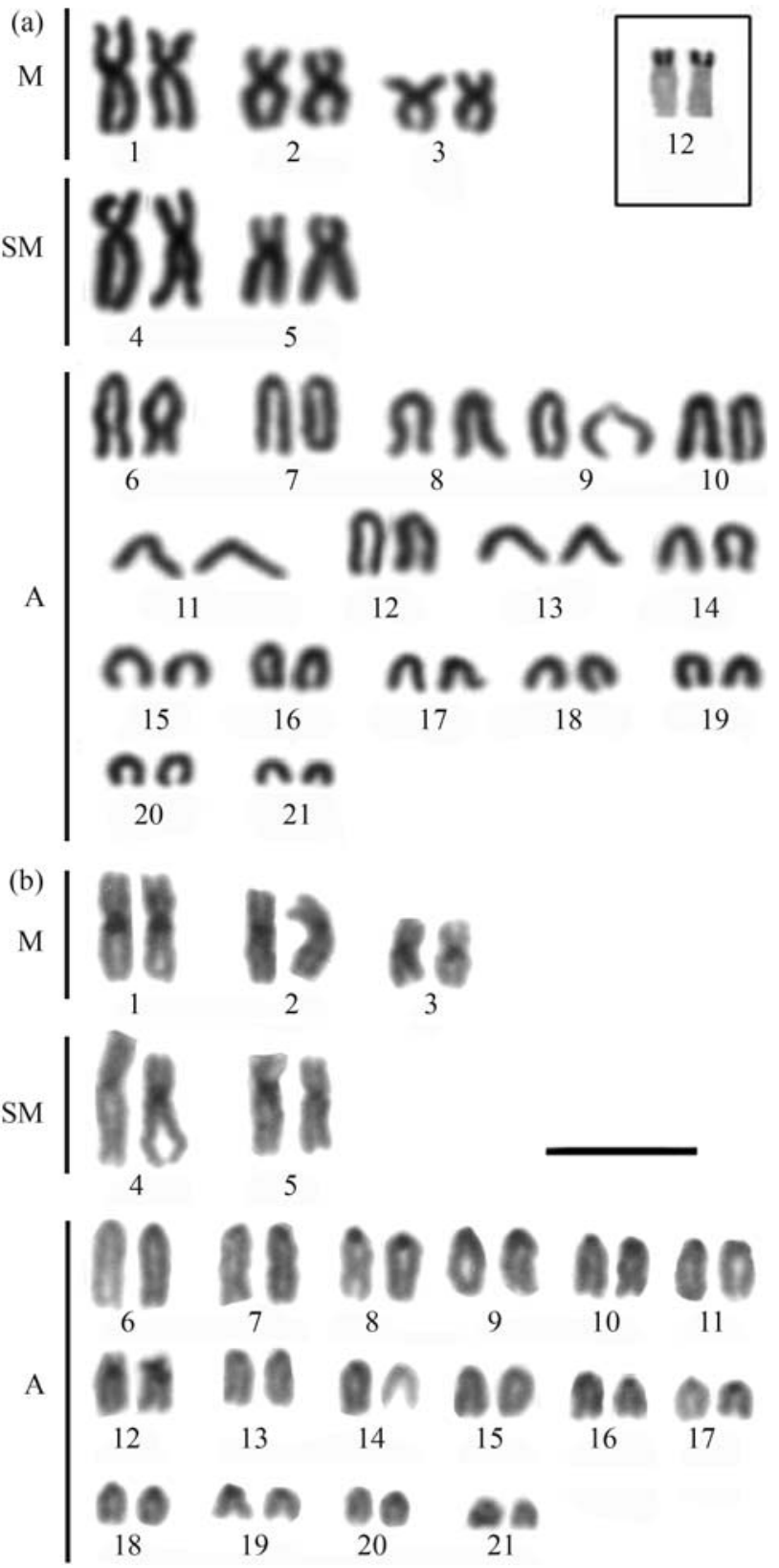

Figure 5 - Karyotype of Muraena pavonina after: (a) Giemsa conventional staining, Inbox, the NOR-bearing pair; (b) C-banding. Bar $=10 \mu \mathrm{m}$.

loid value of $2 n=42$ with several acrocentric chromosomes (Table 1). This would be a basal condition when compared to other Anguilliformes $(2 n=38)$. The variation in diploid numbers is smaller within this family, ranging from $2 \mathrm{n}=36$ to $2 n=42$, with variable fundamental numbers $(F N=42$ to 84). The karyotypes show a wide structural variation mainly due to pericentric inversions, which played a major role in the chromosome evolution of this species group.

$E$. nigricans, $G$. vicinus and $M$. pavonina present unique karyotypes that nevertheless show the pattern of the family Muraenidae with a high number of acrocentric chromosomes, a rare condition in other Anguilliformes. One exception was the karyotype of $G$. miliaris $(2 \mathrm{n}=42)$ that 
Table 1 - Cytogenetic data in species of Ophichthidae and Muraenidae (Anguilliformes).

\begin{tabular}{|c|c|c|c|c|c|}
\hline Species & $2 n$ & FN & Chromosomal formula & Sex chromosomes & References \\
\hline \multicolumn{6}{|l|}{ Ophichthidae } \\
\hline Echelus myrus & 38 & 58 & $20 \mathrm{~m}-\mathrm{sm}+18 \mathrm{a}$ & - & Salvadori et al.,1994; Amores et al., 1995 \\
\hline E. uropterus & 50 & - & - & - & Nogusa, 1960 \\
\hline Myrichthys ocellatus & 38 & 70 & $8 m+14 s m+10 s t+6 a$ & - & *Present data \\
\hline Ophisurus macrorhynchos & 38 & 76 & $20 \mathrm{~m}+14 \mathrm{sm}+4 \mathrm{st}$ & - & Nishikawa and Sakamoto, 1977 \\
\hline Ophisurus macrorhynchos & 38 & 76 & $38 \mathrm{~m}-\mathrm{sm}$ & - & Vasil'ev, 1980 \\
\hline Ophisurus serpens & 38 & 74 & $12 \mathrm{~m}+24 \mathrm{st}+2 \mathrm{a}$ & - & Thode et al.,1985 \\
\hline Pisodonophis boro & 40 & 40 & $40 \mathrm{a}$ & - & $\begin{array}{l}\text { Natarajan and Subrahmanyam, 1974; } \\
\text { Vasil'ev, } 1980\end{array}$ \\
\hline Pisodonophis boro & 38 & 64 & $18 \mathrm{~m}+4 \mathrm{sm}+4 \mathrm{st}+12 \mathrm{a}$ & - & Khuda-Bukhsh and Barat, 1987 \\
\hline Pisodonophis zophistius & 38 & 68 & - & - & Nishikawa and Sakamoto, 1977 \\
\hline Muraenichthys gymnotus & 48 & 52 & $4 \mathrm{st}+44 \mathrm{a}$ & $\mathrm{X}_{1} \mathrm{X}_{1} \mathrm{X}_{2} \mathrm{X}_{2}$ & Murofushi and Yosida, 1984 \\
\hline Muraenichthys gymnotus & 47 & 52 & $1 \mathrm{~m}+4 \mathrm{st}+42 \mathrm{a}$ & $\mathrm{X}_{1} \mathrm{X}_{2} \mathrm{Y}$ & Murofushi and Yosida, 1984 \\
\hline \multicolumn{6}{|l|}{ Muraenidae } \\
\hline Enchelycore nigricans & 42 & 68 & $6 m+8 s m+12 s t+16 a$ & No & *Present data \\
\hline E. pardalis & 42 & 52 & $8 m+2 s m+32 a$ & - & Takai and Ojima, 1985 \\
\hline Gymnothorax eurostus & 42 & 54 & $12 \mathrm{~m}-\mathrm{sm}+30 \mathrm{a}$ & $X Y$ & Manna, 1989 \\
\hline “ & 42 & 54 & - & - & Takai and Ojima, 1986 \\
\hline Gymnothorax miliaris & 42 & 84 & $14 m+18 s m+10 s t$ & - & *Present data \\
\hline Gymnothorax ocellatus & 42 & 76 & $16 \mathrm{~m}+18 \mathrm{sm}+8 \mathrm{a}$ & - & Porto-Foresti et al., 2005 \\
\hline Gymnothorax reevesii & 42 & 76 & - & - & Shoubai et al., 1991 \\
\hline Gymnothorax vicinus & 42 & 56 & $8 m+6 s m+28 a$ & - & *Present data \\
\hline Gymnothorax kidako & 42 & - & - & - & Nogusa, 1960 \\
\hline Gymnothorax kidako & 42 & - & - & - & Vasil'ev, 1980 \\
\hline Gymnothorax kidako & 36 & 60 & $16 \mathrm{~m}+8 \mathrm{sm}+12 \mathrm{a}$ & - & Taka and Ojima, 1986 \\
\hline Gymnothorax pictus & 42 & 42 & $42 \mathrm{a}$ & - & Rishi, 1973 \\
\hline Gymnothorax pictus & 42 & - & - & - & Ojima, 1985 \\
\hline Gymnothorax unicolor & 42 & 54 & $12 \mathrm{~m}-\mathrm{sm}+30 \mathrm{a}$ & No & Deiana et al., 1990 \\
\hline Muraena helena & 42 & 60 & $18 \mathrm{~m}-\mathrm{sm}+24 \mathrm{st}-\mathrm{a}$ & No & Cau et al., 1988 \\
\hline Muraena pavonina & 42 & 52 & $6 m+4 s m+32 a$ & - & *Present data \\
\hline Sideria picta & 42 & 42 & $42 \mathrm{a}$ & - & Takai and Ojima, 1985 \\
\hline
\end{tabular}

presented the highest FN reported so far in Muraenidae $(\mathrm{FN}=84)$, likely due to pericentric inversions.

Karyotypes from both sexes were reported for only a few anguilliform species. Simple sex chromosome systems of the XX/XY type were reported in a muraenid, Gymnothorax eurostus (Takai and Ojima, 1985). A ZZ/ZW sex determination system was identified in some congrid species such as Astroconger myriaster (Park and Kang, 1979; Ojima and Ueda, 1982), Conger japonicus and Alloconger anagoides (Takai and Ojima, 1985) and in some species of the genus Anguilla, although some of these reports have been questioned (Wiberg, 1983; Sola et al., 1984). Multiple sex chromosomes systems are rare within this group, but there is a description of a $\mathrm{X} 1 \mathrm{X} 2 \mathrm{Y} / \mathrm{X} 1 \mathrm{X} 1 \mathrm{X} 2 \mathrm{X} 2$ system in the ophichtid Muraenichthys gymnotus, where females presented
$4 \mathrm{st}+44 \mathrm{a}(2 \mathrm{n}=48)$ and males characterized by $1 \mathrm{~m}+4 \mathrm{st}+42 \mathrm{a}$ $(2 \mathrm{n}=47)$ (Murofushi and Yosida, 1984).

According to Brum and Galetti (1997), diploid and fundamental numbers equal to 48 should be regarded as a synapomorphy for modern Teleosteans (Euteleostei) and Clupeomorpha. Since this trend is observed in these high taxonomic categories, the Anguilliformes (Elopomorpha) seem to have diverged from this pattern as a result of the reduction in the diploid number through chromosomal rearrangements, such as centric or in tandem fusions, followed by pericentric inversions.

In contrast with Perciformes, usually characterized by both numerical and structural karyotypic homogeneity (Molina, 2006), the Anguilliformes revealed structural chromosomal bands that suggest different levels of chro- 
matin organization (Bernardi and Bernardi, 1990; Salvadori et al., 1997; Pichiri et al., 2000; Salvadori et al., 2003).

Although the pattern of heterochromatin distribution is known for only a few Anguilliformes, the available reports indicate the presence of large heterochromatic blocks at pericentromeric positions or encompassing the whole length of the short arms of several chromosomes (Deiana et al., 1990). Despite this, heterochromatic regions in $M$. ocellatus and $M$. pavonina were reduced and restricted to centromeric position on chromosomes. The Atlantic Muraenidae species E. nigricans, G. miliaris and $G$. vicinus presented a higher heterochromatin content with positive C-bands in nearly all chromosomes and some interspecific differences. These results are in agreement with previous studies carried out in this fish family (Cau et al., 1988).

Although the compositional heterogeneity of heterochromatin has been commonly reported in fish (Souza et al., 1996, among others), there are only few examples in marine species (Affonso and Galetti, 2005). Significant differences in heterochromatin composition have been reported in Gymnothorax unicolor and Muraena helena after chromosome digestion with restriction enzymes and CMA3 staining (Salvadori et al., 1997), as well as through comparisons between MboI and 5S rDNA sequences (Pichiri et al., 2000).

Heterochromatinization processes seem to have played an important role in the karyotypic evolution of Anguilliformes. Some studies have pointed out the relationship between a higher heterochromatin content and chromosomal diversity in fish species (Molina and Galetti, 2002; Molina, 2006). In G. miliaris, extensive heterochromatic polymorphisms could be observed in several chromosome pairs. Such polymorphisms involved an expansion of pericentromeric segments (homologues from pairs 2, 13 and 19), increase of the short arms (homologues of pairs 5, 8, 12 and 15) and differences in heterochromatin location between homologues (telomeric/centromeric, pairs 5, 11, 13 and 15).

In $G$. vicinus, size heteromorphisms were identified in pairs 1, 2 and 6, but could not be related to either differences in heterochromatin content or to NORs polymorphisms. Size heteromorphism and interindividual differences in centromere position were detected between homologues of some meta-submetacentric pairs of $G$. miliaris, E. nigricans, $M$. pavonina and M. ocellatus. The amplification of repetitive sequences led to changes in the morphology of many chromosome pairs. There are some reports of this type of heteromorphism within the order Anguilliformes, for instance in the species Conger japonicus, Alloconger anagoides and G. eurostus (Takai and Ojima, 1985).

Polymorphisms of the size of ribosomal sites have already been identified in Anguilliformes (Wiberg, 1983; Sola et al., 1984). Ribosomal sites are present in a single chromosome pair (Salvadori et al., 1994) and four patterns have been reported so far, all of them in Atlantic species: at a terminal location on the long arms of a submetacentric chromosome pair such as observed in $G$. ocellatus (Porto-Foresti et al., 2005); at the telomeres of the short arms of a subtelo/submetacentric chromosome pair (as found herein in M. ocellatus; G. miliaris and E. nigricans); at a terminal position on the short arms of an acrocentric pair (such as in M. pavonina); and at an interstitial position, close to the centromeres on the long arms of an acrocentric pair (observed herein in G. vicinus).

The NOR pattern has been regarded as a potentially useful cytotaxonomic marker to species identification within Muraenidae (Salvadori et al., 1994). Therefore, in $E$. nigricans, Ag-NORs were present on the short arms of a subtelocentric pair (11). In G. miliaris, ribosomal sites were identified on the short arms of a submetacentric pair at a telomeric position (12), and in G. vicinus, NORs were located interstitially on the long arms of an acrocentric pair (11), while in M. pavonina, Ag-NORs were observed on the short arms of an acrocentric pair (12). In the representative of the family Ophichthidae M. ocellatus, Ag-NORs were present on the short arms of pair 13 (acrocentric). Secondary constrictions equivalent to NORs were commonly observed in all analyzed species. Moreover, there was no association of heterochromatic segments with ribosomal sites, as previously observed in other fish groups (Artoni et al., 1999).

Compared to Perciformes (Euteleostei), which often present a basal $2 \mathrm{n}=48$, many acrocentric chromosomes and a low heterochromatic content, the karyotypic pattern of Anguilliformes, as demonstrated in the present study, is characterized by large meta-submetacentric chromosomes and some large acrocentric elements, possibly originated through centric or in tandem fusions, as well as by heterochromatin accumulation. The karyotypic diversity among Atlantic morays and eels is reflected in their unique karyotypes, which can be used for cytotaxonomic purposes.

\section{Acknowledgments}

We thank CNPq, CAPES, and Universidade Federal do Rio Grande do Norte for the financial support to AJMV, and SECIRM for providing the facilities and conditions for this work.

\section{References}

Affonso PRAM and Galetti Jr PM (2005) Chromosomal diversification of reef fishes from genus Centropyge (Perciformes, Pomacanthidae). Genetica 123:227-233.

Amores A, Bejar F and Alvarez MC (1995) Replication, C and Ag-NOR chromosome banding in two anguilliform fish species. Mar Biol 123:845-849.

Artoni RB, Molina WF, Bertollo LAC and Galetti Jr PM (1999) Heterochromatin analysis in the fish species Liposarcus anisitsi (Siluriformes) and Leporinus elongatus (Characiformes). Genet Mol Biol 22:39-44. 
Bernardi G and Bernardi G (1990) Compositional patterns in the nuclear genomes of cold-blooded vertebrates. J Mol Evol 31:265-281.

Bertollo LAC, Born GG, Dergam JA, Fenocchio AS and Moreira-Filho O (2000) A biodiversity approach in the neotropical Erythrinidae fish, Hoplias malabaricus. Karyotypic survey, geographic distribution of cytotypes and cytotaxonomic considerations. Chrom Res 8:603-613.

Bertollo LAC, Oliveira C, Molina WF, Margarido VP, Fontes MS, Pastori MC, Falcão JN and Fenocchio AS (2004) Chromosome evolution in the erythrinid fish, Erythrinus erythrinus (Teleostei, Characiformes). Heredity 93:228233.

Brum MJI and Galetti Jr PM (1997) Teleostei ground plan karyotype. J Comp Biol 2:91-102.

Cau A, Salvadori S, Deiana AM, Bella JL and Mezzanotte R (1988) The characterization of Muraena helena L. mitotic chromosomes: karyotype, C-banding, nucleolar organizer regions and in situ digestion with restriction endonucleases. Cytogenet Cell Genet 47:223-226.

Deiana AM, Salvadori S and Cau A (1990) The characterization of somatic chromosomes of Gymnothorax unicolor (Delaroche 1809) by C-banding and NOR staining (Osteichthys, Anguilliformes). Genetica 81:17-20.

Demirok NK and Ünlü E (2001) Karyotypes of Cyprinid fish Capoeta trutta and Capoeta capoeta umbla (Cyprinidae) from the Tigris River. Turk J Zool 25:389-393.

Devlin RH and Nagahama Y (2002) Sex determination and sex differentiation in fish: An overview of genetic, physiological, and environmental influences. Aquaculture 208:191364.

Gold JR, Li C, Shipley NS and Powers PK (1990) Improved methods for working with fish chromosomes with a review of metaphase chromosome banding. J Fish Biol 37:563-575.

Howell WM and Black A (1980) Controlled silver staining of nucleolus organizer regions with protective colloidal developer: 1-step method. Experientia 36:1014-1015.

Klinkhardt M, Tesche M and Greven H (1995) Database of Fish Chromosomes. Westarp Wissenschaften, Magdeburg, $237 \mathrm{pp}$.

Khuda-Bukhsh AR and Barat A (1987) Chromosomes in fifteen species of Indian teleost (Pisces). Caryologia 40:131-144.

Lee MR and Elder FFB (1980) Yeast stimulation of bone marrow mitosis for cytogenetic investigations. Cytogenet Cell Genet 26:36-40.

Levan A, Fredga K and Sandberg AA (1964) Nomenclature for centromeric position on chromosomes. Hereditas 52:201220.

Manna GK (1989) Fish cytogenetics related to taxonomy, evolution and monitoring aquatic genotoxic agents. In: Das P and Jingran AG (eds) Fish Genetics in India. Proceedings of the Symposium on Conservation and Management of Fish Genetic Resources of India, India, pp 21-46.

Molina WF (2002) An alternative method for mitotic stimulation in fish cytogenetics. Chrom Sci 5:149-152.

Molina WF (2006) Chromosomal changes and stasis in marine fish groups. In: Pisano E, Ozouf-Costaz C, Foresti F and Kapoor BG (eds) Fish Cytogenetics. Science Publishers, Enfield, pp 69-110.

Molina WF and Galetti Jr PM (2002) Robertsonian rearrangements in the reef fish Chromis (Perciformes, Pomacen- tridae) involving chromosomes bearing 5S rRNA genes. Genet Mol Biol 25:373-377.

Molina WF and Galetti Jr PM (2007) Early replication banding in Leporinus species (Osteichthyes, Characiformes) bearing differentiated sex chromosomes (ZW). Genetica 130:153160.

Moreira-Filho O and Bertollo LAC (1991) Astyanax scabripinnis (Pisces, Characidae): A "species complex". Braz J Genet 14:331-357.

Moreira-Filho O, Bertollo LAC and Galetti Jr PM (1993) Distribuition of sex chromosome mechanisms in neotropical fish and description of a ZZ/ZW system in Parodon hilarii (Parodontidae). Caryologia 46:115-125.

Murofushi M and Yosida TH (1984) Cytogenetical studies on fishes. VIII. XX-Y sex chromosome mechanism newly found in the snake eel, Muraenichthys gymnotus (Anguilliformes, Pisces). Proc Jap Acad Ser B 60:21-23.

Natarajan R and Subrahmanyam K (1974) A karyotype study of some teleost from Portonovo waters. Proc Ind Acad Sci Ser B 79:173-196.

Nelson JS (2006) Fishes of the World. 4th edition. John Wiley and Sons Inc., New York, 601 pp.

Nishikawa S and Sakamoto K (1977) A comparative study of chromosomes in Japanese fishes. III. Somatic chromosomes of three anguilloid species. J Shimonoseki Univ Fish 25:193-196.

Nogusa S (1960) A comparative study of the chromosomes of fishes with particular considerations on taxonomy and evolution. Mem Hyogo Univ Agric 3:1-62.

Ojima Y (1985) Fish CDR List. Dept. of Biol. Fac Sci, Kwansei Gakuin University.

Ojima Y and Ueda H (1982) A karyotypical study of the conger eel (Conger myriaster) in in vitro cells, with special regard to the identification of the sex chromosome. Proc Jap Acad 58B:56-59.

Park EH and Kang YS (1979) Karyological confirmation of conspicuous ZW sex chromosomes in two species of Pacific anguilloid fishes (Anguilliformes, Teleostomi). Cytogenet Cell Genet 23:33-38.

Pichiri G, Coni P, Deiana AM, Nieddu M and Mezzanotte R (2000) On the variability of MboI repeated sequences and 5S rDNA in Muraena helena and Gymnothorax unicolor (Anguilliformes, Muraenidae). Chrom Res 8:443-445.

Porto-Foresti F, Oliveira C, Gomes EA, Tabata YA, Rigolino MG and Foresti $F$ (2004) A Lethal effect associated with polymorphism of the NOR-bearing chromosomes in rainbow trout (Oncorhynchus mykiss). Genet Mol Biol 27:51-54.

Porto-Foresti F, Oliveira C and Foresti F (2005) First chromosome characterization in the Neotropical eel, Gymnothorax ocellatus (Pisces, Muraenidae). Cytologia 70:283-286.

Rishi KK (1973) A preliminary report on the karyotypes of eighteen marine fishes. Res Bull Punjab Univ 4:161-162.

Salvadori S, Cau A, Coluccia E, Milia A and Deiana AM (1994) Karyotype, C-banding and G-banding, and nucleolar organizer regions of Conger conger (Osteichthyes, Anguilliformes). Boll Zool 1:59-63.

Salvadori S, Deiana AM, Coluccia E, Milia A and Cau A (1997) The different banding patterns produced by restriction endonuclease digestion in mitotic chromosomes of the American and European eel. J Fish Biol 50:668-671. 
Salvadori S, Coluccia E, Cannas R, Cau A and Deiana AM (2003) Replication banding in two Mediterranean moray eels: Chromosomal characterization and comparison. Genetica 119:253-258.

Shoubai R, Tianguo Z, Wenhui Z and Jiedong C (1991) The karyotypes of Gymnothorax reevesi. Tropic Oceanol 10:98-101.

Sola L and Gornung E (2001) Classical and molecular cytogenetics of the zebrafish, Danio rerio (Cyprinidae, Cypriniformes): An overview. Genetica 111:397-412.

Sola L, Gentili G and Cataudella S (1980) Eel chromosomes: Cytotaxonomical interrelationships and sex chromosomes. Copeia 4:911-913.

Sola L, Camerini B and Cataudella S (1984) Cytogenetics of AtIantic eels: C- and $\mathrm{G}$ banding, nucleolus organizer regions, and DNA content. Cytogenet Cell Genet 38:206-210.

Souza IL, Moreira-Filho O and Galetti Jr PM (1996) Heterochromatin differentiation in the characid fish Astyanax scabripinnis. Braz J Genet 19:405-410.
Sumner AT (1972) A simple technique for demonstrating centromeric heterochromatin. Exp Cell Res 75:304-306.

Takai A and Ojima Y (1985) Karyotypic studies of five species of Anguilliformes (Pisces). Proc Jap Acad Ser B 61:253-256.

Thode G, Alvarez MC, Giles V and Garcia E (1985) Chromosome complement, $\mathrm{C}$ banding and Ag-NOR location in Ophysurus serpens (Ophichthidae, Anguilliformes). Cytobios 43:7377.

Vasil'ev VP (1980) Chromosome numbers in fish-like vertebrates and fish. J Ichthyol 20:1-38.

Wang CH, Kuo CH, Mok HK and Lee SC (2003) Molecular phylogeny of elopomorph fishes inferred from mitochondrial 12S ribosomal RNA sequences. Zool Scripta 32:231-241.

Wiberg UH (1983) Sex determination in the European eel (Anguilla anguilla. L.). Cytogenet Cell Genet 36:589-598.

Associate Editor: Fausto Foresti

License information: This is an open-access article distributed under the terms of the Creative Commons Attribution License, which permits unrestricted use, distribution, and reproduction in any medium, provided the original work is properly cited. 